DE DE GRUYTER OPEN
Journal of Intercultural Management

Vol. 6, No. 3, September 2014, pp. 37-55

DOI 10.2478/joim-2014-0018

Małgorzata Bartosik-Purgat

Poznan University of Economics

\title{
Cultural traits of the future managers from generation $Y$ - an example of young Europeans
}

\begin{abstract}
On the one hand, internationalization and globalization processes influence the fact that attitudes and behaviours of representatives of different cultures become similar. On the other one, opposite processes which aim at the manifestation of cultural differences can be observed.

The aim of this article is to find an answer to the question whether young people, students of higher schools of economics, future managers show similar cultural traits or whether the influence of the native environment is so strong that young Europeans manifest different values. In order to answer this question selected characteristics, which are significantly applicable at work in an enterprise have been used.

The answer to the aforementioned question has been searched both in the literature on the subject as well as in empirical studies conducted in ten European countries (Belgium, the Czech Republic, Finland, France, Spain, the Netherlands, Germany, Poland, Portugal, Great Britain). Their results show significant similarities of cultural traits among the young respondents coming from the surveyed countries. These characteristics are manifested in various attitudes, hypothetical behaviours and the judgment of behaviour of others.
\end{abstract}

Key words: national culture, generation $\mathrm{Y}$, young Europeans

\section{Introduction}

Benefits which stem from the standardization of activities and refer among others to the economies of scale reached in an international activity contribute to the situation in which the activities of enterprises in foreign markets become similar. It is also influenced by the circumstances on the side of the demand which is connected with convergence processes based on the interpenetration of cultural traits 
between markets and cultures. In other words, societies learn customs, behaviour, lifestyle of others and sometimes acquire these traits while getting away from tradition and values typical of their native culture [Hoque et al., 2011, pp. 23-25; Gupta V., Wang J., 2004, p. 39]. On the other hand, divergent processes are more and more often observed, especially in highly developed countries. They are characterized by an opposite trend connected with emphasising cultural membership and elevating these traits over other ones - foreign [Ogbor J.O., Williams J., 2003, p. 3; Živko T., 2006, pp. 1025-26].

On these grounds the segments of people who are more susceptible to being influenced by other cultures and acquiring their traits and ethnocentric groups are distinguished. Among the former ones mainly young, well-educated people who know foreign languages, travel a lot and are open to adapt customs from other cultures are distinguished. In the article Global youth united: homogeneous group prime target for U.S. marketers A. Parmar states that young people (the so called young adults) are a segment having convergence traits on a global scale. At the same time he emphasises their significant purchasing power (although he does not analyse the source of funds) and great inclination toward spending money which make them heavily influence the activities of enterprises [Pamar A., 2002, p. 1-48] $]^{1}$. According to antiglobalists, N. Klein among others, the media, especially television, play an important role in creating ,global youth”. Through television young people (regardless of national culture and where they live) share the way they dress, use advertised goods or eat similar food in global chains like McDonald's [Klein N., 2004, p. 134]. A certain criterion of similarity is also education. Some common characteristics, regardless of a country, can be noticed among young people graduating from universities of economics, humanities or technology. Education directs a certain way of thinking, world view, attitudes toward different situations and their judgement. Young people graduating from faculties of economics judge changing conditions, foresee possible scenarios or make decisions in a different way than graduates with humanities degree, e.g. in history, art studies, psychology etc.

On the other hand, among those more „resistant” to cultural influences of other societies people who are elder, poorly educated, without the knowledge of foreign languages and reluctant to go abroad are mentioned [Ogbor J.O., 2000, p. 50]. However, it is not a rule concerning all foreign markets. The financial crisis caused that even among the young parts of societies nationalist attitudes are prevalent, e.g. France, Spain.

\footnotetext{
1 Similar theses are pointed out by many researchers and scientists who claim that young consumers are „free” from cultural influences in their actions. Such conclusions are formulated by S.M. Choi and C.L. Ferle among others on the basis of the surveys conducted among the Korean and American youth (the so called young adults) [2004, pp. 490-495].
} 
The aim of this article is to find an answer to the question whether young people, students of higher schools of economics - future managers show similar cultural traits or whether the influence of the native environment is so strong that young Europeans manifest different values. The article has been written on the basis of the literature on the subject and empirical studies conducted by the author in ten European countries ${ }^{2}$. In order to answer this question selected characteristics, which are significantly applicable at work in an enterprise have been used.

\section{Literature overview}

Classifications of national cultures distinguished in the literature are very useful in terms of conducting business activities in the markets of particular cultural groups. While researching cultural roots of national types of behaviour, both in social as well as business areas it can be highly predicted how members of a particular society (foreign market) will react to different situations and problems, which is very important when establishing cooperation or solving conflicts etc. Previous studies conducted internationally have made it possible to distinguish certain cultural dimensions which are particularly characteristic of cultural groups. Among the most widespread studies the research conducted by F. Trompenaars, Ch. Hampden-Turner, G. Hofstede and their collaborators and the GLOBE project (under the supervision of R.J. House) should be indicated. The aforementioned studies conducted among enterprises on many foreign markets show the specificity of their organizational cultures and, at the same time, cultural traits of a given society. Organizational cultures of enterprises are created by people who behave in a particular way, conform to certain values, customs, norms etc. Some of the dimensions strictly correspond to the behaviour of individuals - people who co-create an organization, therefore to relationships, differences between supervisors and employees [Lee S.M., Peterson S.J., 2000, p. 406]. The question asked frequently in modern literature refers to homogeneity of managerial characteristics of today's managers in the international arena. Is it possible to talk about specific management styles which are only characteristic of a specific country/culture or is it possible to "expand" them also to other markets [Jacob N., 2005, p. 515; Kirsch Ch., Chelliah J., Parry V., 2011, p. 165]? There are countries such as Canada or Switzerland where cultural differentiation influences the diversity of management styles within one country (depending on which region an enterprise comes from). On the other hand, globalization processes and increased internationalization contribute to employing in branches of international companies people from different countries and cultures [Dong K., Liu Y., 2010, p. 224; Yeganeh H., 2011, pp. 329-330] and representatives of various generations, i.e. the so called baby-boom generation (1946 - 64),

\footnotetext{
2 The majority of presented results were obtained within the research project funded by the Ministry of Science and Higher Education nr 1 HO2D 00527.
} 
generation X (1965-1980) or generation Y (1981-2000). It may cause obliteration of dissimilarity in the specificity of the activity of enterprises.

\section{Generation Y}

Representatives of generation $\mathrm{Y}$, which developed very quickly, are the youngest generation group in the society dominated by new technologies. As employees they are characterized by the development toward structuring (division of tasks, procedures etc.) and focusing on work [Wendover R.W., 2007, p. 75]. In comparison to generation $\mathrm{X}$ they are more active in social and sport activities and believe that their work and involvement matter in today's world. Although the representatives of generation $\mathrm{Y}$ are the youngest employees in enterprises they learn quickly and want to be „up-to-date” with all new technological solutions. Generation Y consists of people who are ones of the best educated adults and are geographically mobile [Altimier L., 2006, p. 8; Kwok H., 2012, p. 234]. They demand from their supervisors and co-workers clear presentation of tasks which are to be done [Gursoy D., Chi C., Karadag E., 2013, p. 43]. Solnet and Hood (2008) distinguished the values which are recognized by the representatives of generation $\mathrm{Y}$ and connected with work. These values include respect, appreciation, involvement, constant development, honesty and concern for individuals [Solnet D., Hood A., 2008, p. 65; Chi Ch.G., et al. 2013, p. 44]. The results of other studies conducted among the representatives of generation $\mathrm{Y}$ prove that they feel most comfortable in organizations (enterprises) where they can develop themselves, have vast choice of projects to work on, conditions to learn and develop new skills, and are provided with flexible schedules as well as a piece of "game" in their work [Altimier L., 2006, p. 8]. Next, Broadbridge and others state that generation $\mathrm{Y}$ has the tendency to be more cooperative, is less hierarchical, has more altruistic attitude, is eager to delight in work and appreciates freedom and independence in making decisions [Broadbridge A.M., et al. 2007, p. 985; Kwok 2012, p. 233].

On the other hand, L. Altimer asks what should be done to motivate generation $\mathrm{Y}$ in organizational structures. He answers stating that first of all, loyalty should not be expected from them. The representatives of generation Y regard employment as a possibility (and even an opportunity) to earn money. Secondly, they should be given maximum independence and flexibility in acting and a possibility of selfmanaging. Thirdly, they should be enabled to have access to new technologies and trainings (the choice of workplace and interest in it often depend on the availability of trainings). Fourthly, they should be allowed to participate in interesting and developing tasks and projects [Altimier L., 2006, p. 8].

\section{Cultural dimensions}

The following subsections present the selected (according to the extent to which they can be applicable in work of future managers) cultural dimensions 
distinguished in the studies conducted by G. Hofstede, F. Trompenaars and Ch. Hampden-Turner, R. House et al, R. Gesteland; it is emphasized in which projects they have been described. The characteristics have been selected according to how essential they are in managerial work. They include: individualism - collectivism, universalism - particularism, specific - diffuse, status achieved - status ascribed, internal direction - external direction, monochronicity - polichronicity, low - high degree of uncertainty avoidance, great - small power distance, masculinity - femininity [Yeganeh H., 2013, pp. 54-60; Kirsch Ch., Chelliah J., Parry V., 2011, pp. 164-166; Clausen L., 2010, p. 58-59]. Moreover, these dimensions were measured in empirical studies concerning the degree of similarity in the researched European countries.

Individualism - collectivism (presented in the studies by G. Hofstede, F. Trompenaars and Ch. Hampden-Turner and in the GLOBE project - here with the distinction between institutional and intra-group collectivism) - this distinction refers to the way of perceiving an individual - an individual person and a group. In individualistic cultures particular individuals, individual work and the results achieved by individuals are of high importance. Everyone works for their own success and is individually responsible for that. On the other hand, in collectivistic cultures a group and being its member matter, while a group can be interpreted as a society, organization or family. An individual works for a success of a group - an enterprise which is responsible for this activity [House R., et al. 2002, pp. 5; Trompenaars F., Hampden-Turner Ch., 1997, p. 54, Hofstede G., p. 52-64; Minkov M., Hofstede G., 2011, p. 10-20]

Universalism - particularism (a dimension distinguished in the studies by $\mathrm{F}$. Trompenaars and Ch. Hampden-Turner) - it refers to the compliance with legal and social norms valid in a particular society. In universalist cultures the regulations which are valid in a given country/culture are applied regardless of the nature and importance of a situation as well as attendant circumstances. On the other hand, in particularistic countries the specificity of a situation is taken into account. It is judged not only because of valid norms but also needs and problems of people are taken into account [Trompenaars F., Hampden-Turner Ch., 1997, p. 30-43].

Specific - Diffuse (a dimension distinguished in the studies by F. Trompenaars and Ch. Hampden-Turner) - refers to connecting private and professional spheres. Diffuse is characterized by interpenetration of and joining professional matters with private life. Relationships beyond enterprise (after work) are the same as in the workplace. On the other hand, specific societies disconnect a professional sphere from private life. A manager is a supervisor for his or her employee only during work time. After work, an employee usually does not use titles connected with the job (organizational hierarchy is not applicable) [Trompenaars F., Hampden-Turner Ch., 1997, p. 83-90]. 
Status achieved - Status ascribed (a dimension distinguished in the studies by F. Trompenaars and Ch. Hampden-Turner and the GLOBE project as an attitude toward efficiency) In some societies status is given to people on the basis of their achievements. They are the so called "achievement cultures" where the achieved status refers to what and how something is done. Other cultures give status for example because of age, class membership, sex, the connections one has and education. They are the so called "ascription cultures" where the ascribed status refers mainly to who one is. In ascription societies higher positions are rather occupied by elder people. It is very tactless to send there young talented high-level managers to hold business talks with people 20 years older than them who occupy particular positions e.g. because of age and experience. In "achievement cultures" a high position can be achieved by a young person through constant striving to reach new and better goals as well as personal development [Trompenaars F., HampdenTurner Ch., 1997, pp. 106-108].

Influence of external factors on making decisions/attitude towards environment (a dimension distinguished in the studies by $\mathrm{F}$. Trompenaars and $\mathrm{Ch}$. Hampden-Turner) - it refers to the dependence of the activity of an individual on external factors. In outer-direction societies (external control) people believe that what is happening in their lives does not depend on them but on other factors. On the other hand, in internal-direction cultures course of events, decisions and people's attitudes in certain situations depend on the people themselves, no one and nothing can influence it [Trompenaars F., Hampden-Turner Ch., 1997, pp.145-147].

Perceiving time (a dimension distinguished in the studies by F. Trompenaars and Ch. Hampden-Turner, E.T. Hall, as well as R.R. Gesteland) In the studies by F. Trompenaars and $\mathrm{Ch}$. Hampden-Turner two groups of societies are distinguished. In the first group time is perceived as sequential (linear), thus "is treated as a sequence of passing events", whereas in the second one it is synchronous (nonlinear), so "the past, present and future are interconnected in such a way that visions referring to the future and memories from the past create the present". Typical features of sequential-time cultures correspond to the characteristics formerly described by E.T. Hall and R.R. Gesteland which are typical of a monochronic group (monochronic cultures are characterized by punctuality, precision, making plans and realizing them consistently). On the other hand, synchronous-time cultures correspond to the characteristics of a group presented as polichronic (polichronic cultures are characterized by treating time with flexibility, lack of schedules and rush) [Trompenaars F., Hampden-Turner Ch., 1997, pp. 125-129; Gesteland R.R., 2001, pp. 56-60].

Attitude towards challenges, new situations, i.e. uncertainty avoidance (UN): high and low degree (a dimension distinguished in the studies by G. Hofstede and in the GLOBE project - refers to behaviour in new unknown situations). In cultures with a low degree of uncertainty avoidance people have a positive 
attitude towards the future, unknown and uncertain situations which may occur [Hofstede G., 1997, p. 109; House F. et al. 2002, pp. 5-6; Minkov M., Hofstede G., 2011, p. 10-20]. On the other hand, in societies with a high degree of uncertainty avoidance people are more pessimistic as far as the unknown and uncertain future is concerned (they make risky decisions more rarely, rarely change their uncomfortable situation because it is what they know and every change is connected with uncertainty) [Kirsch Ch., Chelliah J., Parry W., 2011, pp.167-168].

The meaning of hierarchy, i.e. power distance (a dimension distinguished in the studies by G. Hofstede and the GLOBE project) - it refers to an extent to which members of a given society accept the fact that there are significant differences in power (jobs, positions) between people both in a society, organizations as well as in a family. A high degree of power distance is connected with accepting a hierarchical set of roles in an organization or society. On the other hand, a low degree of uncertainty avoidance refers to egalitarianism in various areas [Hofstede G., 1997, pp. 140-145; House F., et al. 2002, p. 6; Minkov M., Hofstede G., 2011, p. 10-20].

Masculinity - femininity (distinguished in the studies by G. Hofstede and the GLOBE project as two dimensions: assertiveness and gender equality) - it refers to values dominant in a given society. In femininity cultures the values are set on a man, concern about his quality of life (people work to live), helping weaker ones whereas masculinity cultures focus on achieving a success, competition is prevalent (people live to work), "strong" and unsusceptible individuals are promoted [Hofstede G., 1997, p. 79-90; House F., et al. 2002, pp. 5-6; Minkov M., Hofstede G., 2011, p. 10-20].

In the following part of the article the author presents the results of the studies obtained within the project concerning identification of the aforementioned cultural traits of young Europeans.

\section{Methodology}

The research whose results are presented below was conducted in 10 European countries (Poland, the Czech Republic, Germany, Finland, France, Belgium, the Netherlands, Spain, Portugal and Great Britain) among young people who were students of colleges of economics (aged 18-30), and was finished in 2012. Its main aim was to identify cultural traits of young Europeans which could influence their behaviour, attitudes and managerial decisions in the future. The results presented in the article are only a part of the whole project. The main research question is to answer the question whether there are differences among young Europeans regarding to their cultural traits. Basing on the literature and observations of the young Europeans consumers' behavior in context of the presented matter, the following hypothesis was advanced and verified: there is a differentiation between young Europeans with regard to the nature and level of importance of values and behaviors. 
The research was conducted as a survey with the use of the distributed questionnaire and a non-random sampling technique, i.e. snowball sampling [Schroeder J., Bartosik-Purgat M., Mruk H., 2013]3. The first group of the respondents was selected by the persons conducting the research (collaborating with the author on particular markets). Then, they were asked to choose other (subsequent) individuals. As a result, in the research participated in total 1519 respondents, including 391 Polish, 149 Czech, 128 Spanish, 164 Portuguese, 82 French, 82 Belgian, 75 Dutch, 183 German, 146 Finn and 119 British respondents. Majority of respondents in all countries were in the age group $18-25$ years. Regarding to the gender the cultural groups were similar in all the surveyed countries (any gender didn't dominate).

\section{The results of empirical studies ${ }^{4}$}

The young Europeans were asked to answer the questions concerning their behaviour in certain situations, express their opinion on the behaviour of others or give their opinion on a particular subject. Since the majority of the researched persons declared willingness to work in the acquired profession these exercises aimed at identifying their traits with reference to the aforementioned characteristics which can be helpful in presenting attitudes and behaviour of the future managers.

\section{Individualism/collectivism}

While referring to individualistic and collectivistic values the young Europeans demonstrated discrepancy in the presented views (Figure 1) ${ }^{5}$. Future Belgian, Dutch, Spanish, Czech and French managers decidedly stood for individualistic behaviour and values, thus it should be concluded that in the future they will present such attitudes at work (individualism, working for one's own success, individual success, individual responsibility etc).

3 Snowball sampling is a non-probability method. The group chosen with this method is unrepresentative. The results obtained in the presented research should not be treated as general for the total population of young Europeans coming from the researched countries. The results are only characteristic of the groups of young consumers who participated in the research.

4 A detailed description of the research methodology and all the results have been presented in: [Bartosik-Purgat M., 2011].

5 The young Europeans were asked to point out support for or negation of the presented attitudes (collectivistic or individualistic), e.g. "Everyone bears individual responsibility for their actions, even if they work in a team" or "If someone works in a team the responsibility for actions of each member is held by the team". 
Figure 1. The importance of the collectivistic and individualistic values

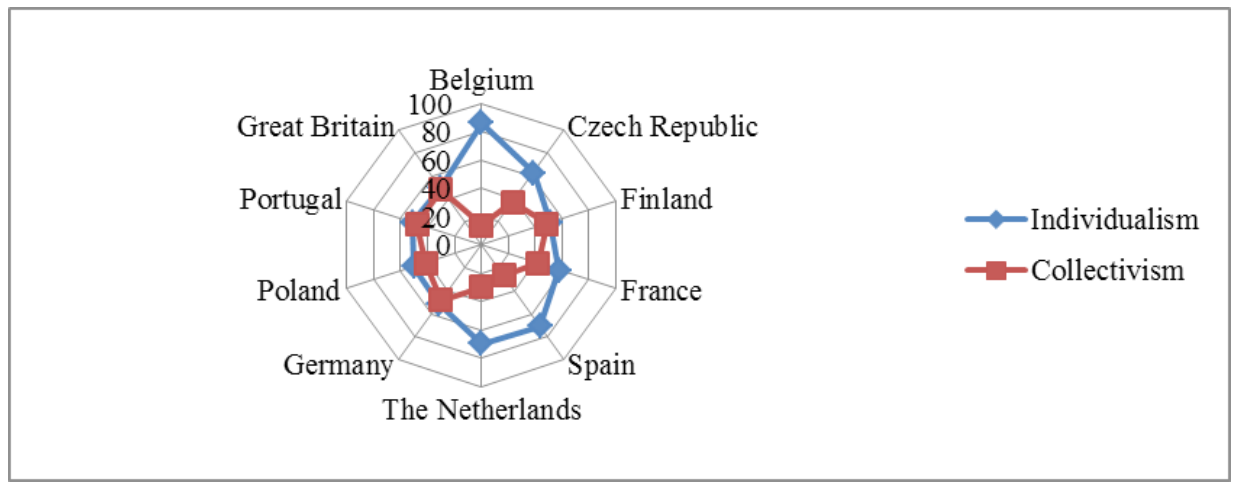

Source: own research.

In the other countries, that is Finland, Germany, Poland, Portugal and Great Britain significant prevalence of individualistic or collectivistic values has not been noticed. The results show moderate attitude towards both dimensions. Therefore, it is difficult to unambiguously identify or predict the traits of future managers while referring to the discussed scope.

\section{Universalism/particularism}

Working in an international enterprise or corporation is connected with constantly making decisions referring to the compliance with valid norms or legal regulations etc. It is an aspect which was measured among the researched sample of the young Europeans. They were supposed to empathise with the stated problem in which making a decision was connected with, on the one hand, strict compliance with the law (universalism) and, on the other one, departure from accepted norms (particularism). The obtained results are presented in Figure 2. where, in comparison to the previous dimension, much greater similarity between the researched countries can be observed. In the vast majority of countries, that is Belgium, the Czech Republic, France, the Netherlands, Poland, Portugal or Great Britain the moderate support for universalistic or particularistic values is prevalent. 
Figure 2. Universalistic and particularistic behavior of young Europeans

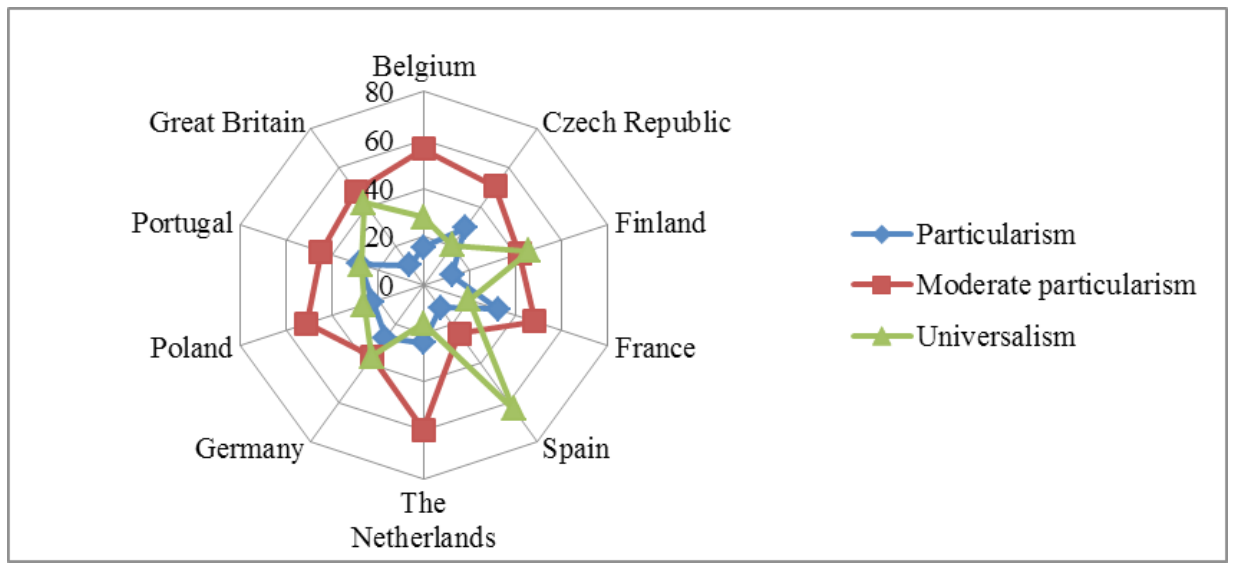

Source: own research.

On the other hand, in Spain significant prevalence of universalistic traits has been observed which denotes that the young people who were researched and future Spanish managers will make their professional decisions strictly according to valid legal norms and accepted rules. The results obtained in Finland and Germany can be similarly commented on, however here in contrast to Spain, the prevailing support for universalistic traits has not been received. The attitudes of young Germans or Finns are not surprising because these cultures belong to societies where all legal regulations are strictly followed. Nevertheless, the results obtained in Spain aroused interest and triggered the necessity of further analyses. They showed that the results in the Spanish sample were influenced by the specificity of the region where the research was conducted. It was Catalonia which is famous for industriousness, diligence and achieving the goals that have been set.

\section{Specific-oriented/diffuse-oriented}

Working as a manager also involves establishing relationships with other coworkers (employees, superiors). In some countries professional relations and hierarchies are transferred to "private grounds", i.e. a manager is a manager irrespective of whether an employee meets him or her in the corridor of the company or when walking a dog (diffuse-oriented approach). On the other hand, in other countries relations from the workplace are not valid in situations after work (specific-oriented approach). The young Europeans were asked to describe their behaviour in hypothetical situations in which the degree of interpenetration of private and professional spheres can be recognized. Figure 3. presents the results obtained in empirical studies which show prevalence of diffuse-oriented approach among young respondents from Belgium, the Czech Republic, France, the Netherlands, Germany 
and Portugal. These results can be slightly surprising since very assertive behaviour is prevalent among young people, which is attributed to specific. However, young age of respondents could have influenced the majority of diffuse behaviours because young people (especially not yet employed - students) have respect for the supervisors.

Figure 3. Specific and diffuse behavior of young Europeans

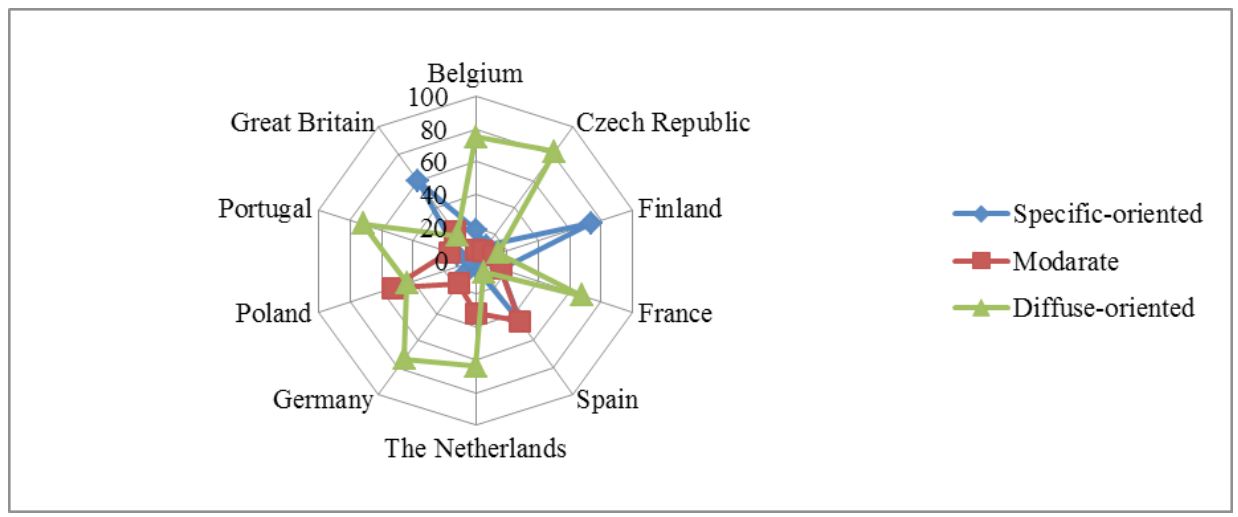

Source: own research.

The prevalence of specific behaviours in Finland and Great Britain is not surprising since they are egalitarian cultures with flat organizational structures where the boss is the employee's partner, parents are partners in relationships with their children etc. Interesting results were obtained in Catalonia where the smallest number of people chose a neutral solution or specific variation.

\section{Status achieved/ascribed}

In some countries the position and status which a given person has within an organization (enterprise) is connected with what a given person has achieved. On the other hand, in other cultures it is thought that the status can be achieved either with age (respect for the elderly, e.g. Asian countries) or in relation to being a member of an appropriate class, origin etc.

In all the researched countries an opinion that the status of an individual should depend on his or her life achievements and not age or origin (in the Netherlands it gained $100 \%$ of support) gained definitely greater support. The second view approving the ascribed status gained the greatest support in the Spanish group (Figure 4). It is therefore advisable when preparing business meetings between representatives of different cultures to take into account the fact that young persons occupying high positions should not participate when in another group of participants there are elder persons holding parallel positions. 
Figure 4. Attitude to way of determining status of the organization

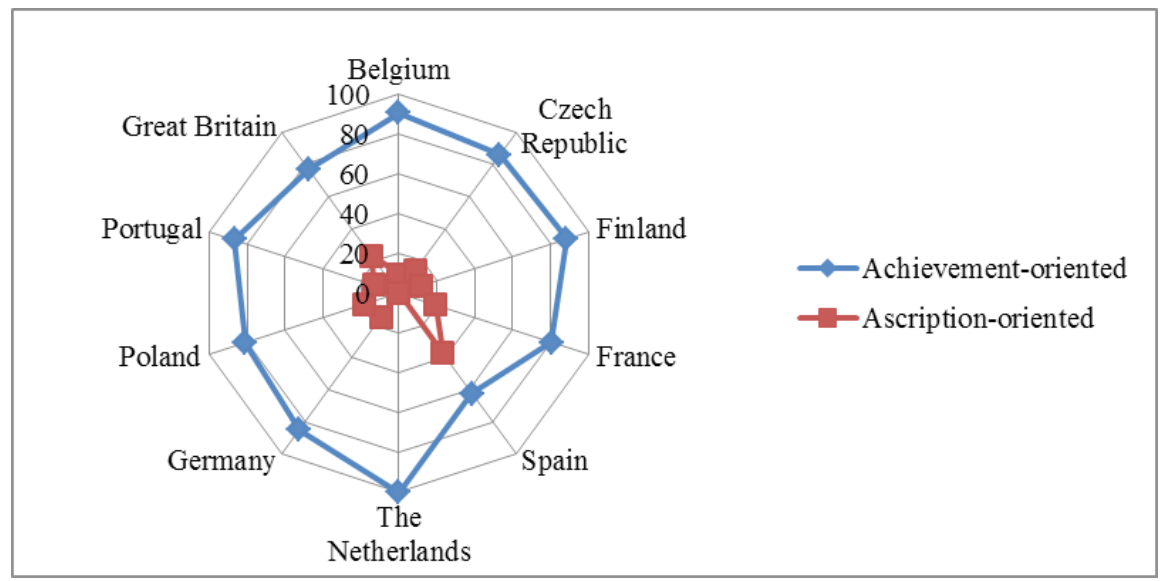

Source: own research.

\section{Internal/external control}

While referring to the dependence in actions (also in making decisions) young Europeans emphasize mainly their self-reliance and the dominant attitude towards environment and other external factors (Figure 5). In their opinion all achievements and merits should be attributed to their own actions and should solely depend on work and actions of individuals. The highest percentage of support for the opinion on the dependence of actions and decision on external factors was found in the group of young Catalonians and Czechs. The characteristics of internally directed groups also include a flexible attitude, willingness to compromise and living with harmony with the nature (acceptance of the nature).

In managerial work organization and planning are indispensable. However, there are significant differences between cultures which refer to the way of perceiving and respecting time. Young Europeans show unusually similar attitude to treating time, i.e. punctuality, obeying schedules, planning etc. (Figure 6). Almost all the respondents presented the above the average level of monochronicity, therefore they proved to appreciate punctuality while having meetings and respect previously made decisions (plans). However, it is not a very high level of monochronicity. What influences this attitude to time is, on the one hand, the young age of the respondents and, on the other one, education they get, that is higher education in economics. This in turn teaches students to respect time, since "time is money". 
Figure 5. Internal and external control in the organization

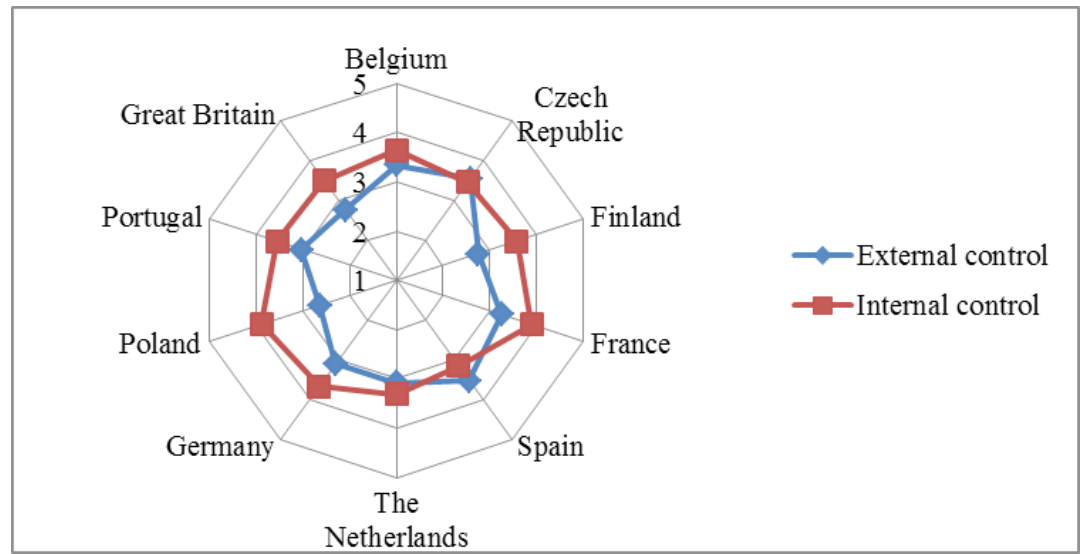

Source: own research.

\section{Attitude to time}

Figure 6. Attitude to time among young Europeans - degree of monochronicity

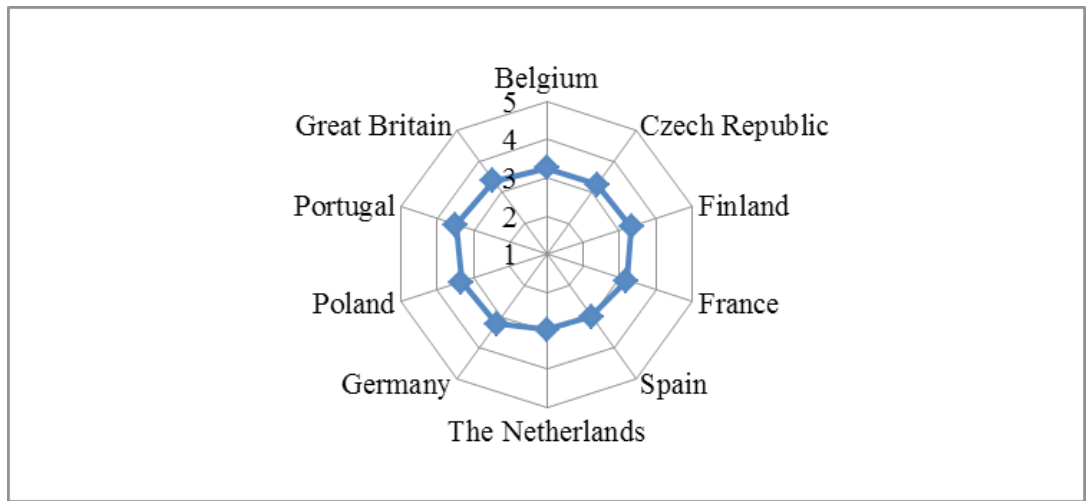

Source: own research.

It is interesting that even in the Spanish and Portuguese groups, which are stereotypically considered to be polichronic (treating time with flexibility) the obtained result was rather high, which denotes their monochronic approach (what is more, the young Portuguese respondents reached the highest degree of monochronicity among the researched cultural groups). 


\section{Uncertainty avoidance}

An essential trait of a manager influencing the length of a decision-making process and the manner in which decisions are made is the degree of uncertainty avoidance. It is an indicator of sensitivity to changes, situations which are new and difficult to predict as well as various innovations. In cultures with a low degree of uncertainty avoidance there is a greater respect for what is different and new. The things that can also be observed are greater proneness to risk and great respect for young people. In cultures with a low degree of uncertainty avoidance decisions are made more easily and quickly because there is no the so called fear of tomorrow (the future). The process of considering and discussing particular alternatives is much shorter than in cultures with a high degree of uncertainty avoidance. On the other hand, the representatives of cultures with a high degree of uncertainty avoidance claim that the future brings danger because it is unknown. They are afraid of all changes and new things. They are also characterized by the lack of proneness to take risk, strong nationalism and concern for safety.

Figure 7. Uncertainty avoidance of young Europeans

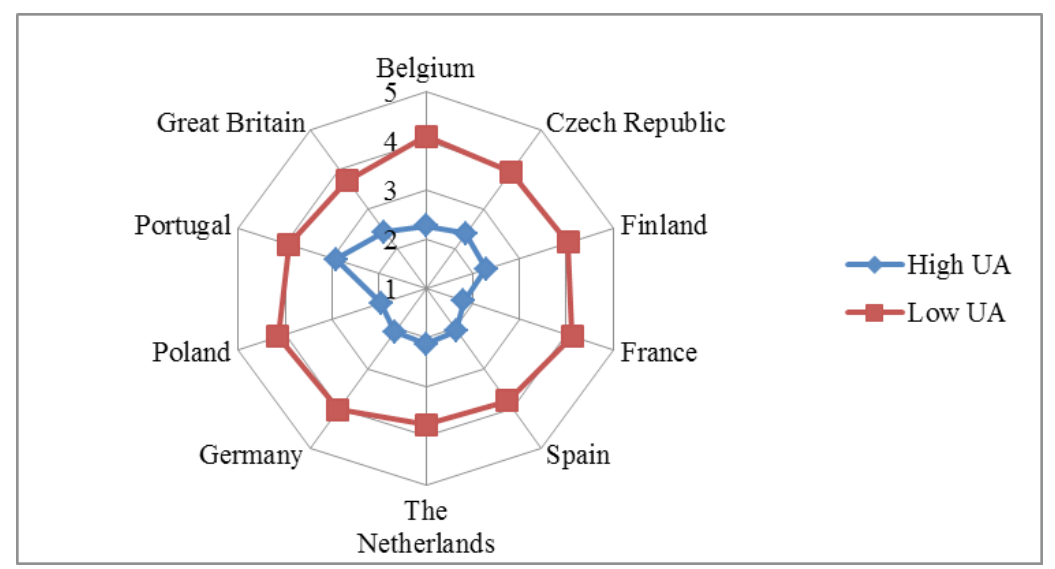

Source: own research.

The results of the research conducted among young Europeans show that in all cultural groups the theses regarding the low degree of uncertainty avoidance, that is the lack of concern for a new, unknown day which should be taken with openness and joy gained greater support.

\section{Power distance}

Working in an organization involves the division of roles, dependence and differences between the employed people. In societies characterized by a great power distance not only within a family but also at a workplace a person who is at the top 
of a hierarchy makes the final decision. If such a person does not participate in a business meeting it should be expected that it will take longer to make a decision because its participants will certainly pass on all arrangements on the basis of which a decision-maker will give his or her opinion. In cultures with a high degree of power distance high positions in an enterprise are usually occupied by elder people who are often there because of their age, vast experience or origin.

Figure 8. The degree of hierarchy's recognition among young Europeans

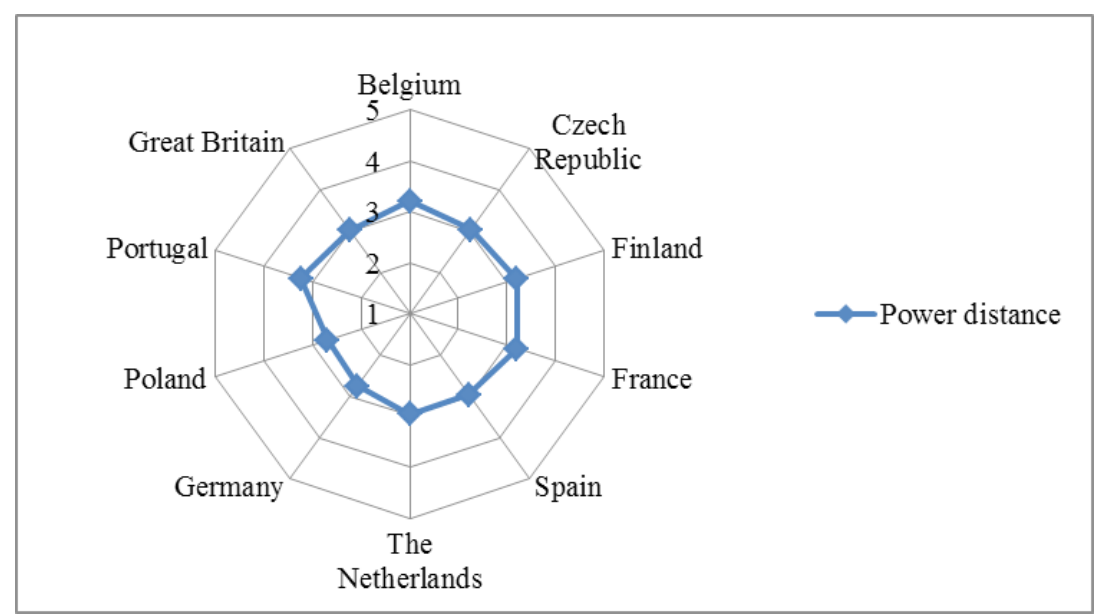

Source: own research.

In the research conducted among the young Europeans the degree of hierarchicity was measured with the use of theses concerning the necessity of showing respect to older people, supervisors etc. The higher the degree of conformity with these opinions the greater the power distance. General results in all the surveyed countries show the average (slightly above the arithmetic mean) degree of hierarchicity with regard to supervisors. The highest level of power distance was obtained in the Portuguese, French and Fin groups. It means that the representatives of these countries support the thesis concerning respect and esteem for supervisors. However, the differences between the other researched countries are insignificant (Figure 8).

\section{Masculinity/femininity}

Hierarchy and differences between people are also connected with behaviour promoting characteristics considered as masculine. Masculine traits in an organization concern focus on a success, achievements or competition. In societies with the intensification of masculine traits high managerial positions are usually occupied by men. 
Figure 9. The degree of masculinity among young Europeans

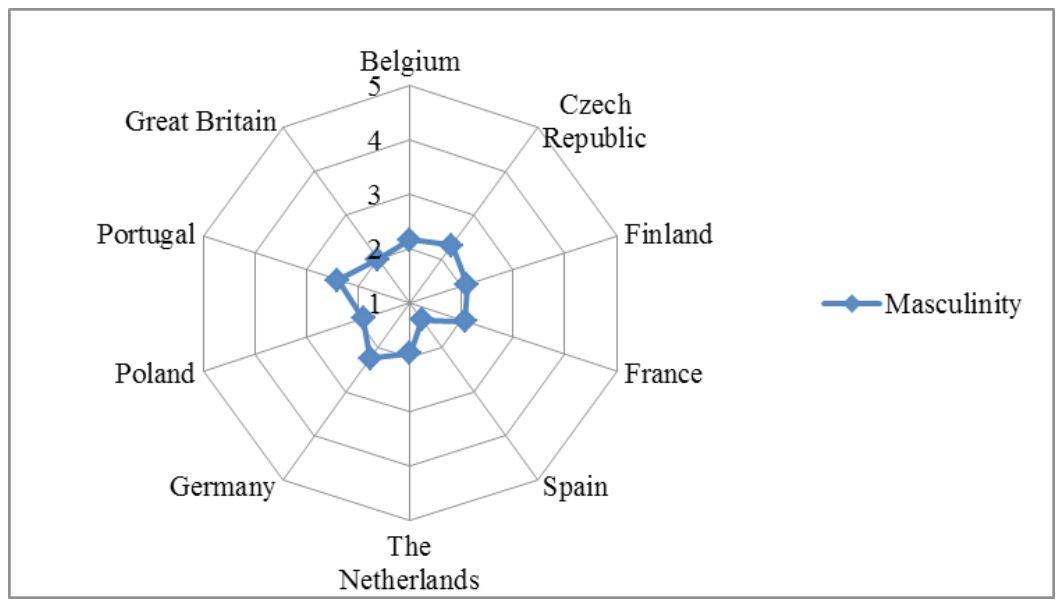

Source: own research.

The young Europeans, when asked about conformity with the statements presenting behaviours and attitudes of a masculine society supported these theses insignificantly (unequivocal agreement among the surveyed respondents can be observed). The largest average indicating the dominance of masculine traits was obtained in Portugal, however, it is the result not exceeding even the arithmetic mean for the scale used (Figure 9). The smallest indication of expression of masculine features is obtained in the group of young Catalans.

\section{Summary}

When summing up the results of the research conducted among the young Europeans, students of higher schools of economics, future managers a definite similarity regarding the distinguished cultural traits should be emphasised. Table 1. presents a comparison of the cultural dimensions introduced in the theoretical and empirical parts as well as the degree of similarity obtained in the ten researched countries.

Table 1. The degree of similarity of cultural features among young Europeans*

\begin{tabular}{|l|l|}
\hline Cultural dimension & The degree of similarity \\
\hline Individualism/collectivism & \pm \\
\hline Universalism/particularism & + \\
\hline Specific-oriented/diffuse-oriented & \pm \\
\hline Status achieved/ascribed & + \\
\hline Internal/external control & + \\
\hline Monochronicity/polichronicity & + \\
\hline
\end{tabular}




\begin{tabular}{|l|l|}
\hline High UN/low UN & + \\
\hline Hierarchicity (average degree) & + \\
\hline Masculine values (low degree) & + \\
\hline
\end{tabular}

$*+$ Very similar, i.e. the majority of the researched countries present the same attitudes, behaviours, stances etc.

$* \pm$ Moderate, half of the researched countries present the same attitudes, behaviours, stances etc.

*-Varied, i.e. there is a significant differentiation of particular attitudes, behaviours, stances etc. among the researched countries

Source: own research.

Similarity in the presented views or hypothetical behaviours of young Europeans have been observed in almost all areas (that means that the hypothesis has not been positively verified). The greatest differentiation has been observed with reference to the degree of acceptance of individualistic and collectivistic values as well as interpenetration of private and professional spheres in everyday life. It should be emphasized that as far as the "specific/diffuse" dimension is concerned despite the fact that in the majority of countries the respondents stood for the diffuse the author has recognized it as a moderate degree of similarity since in the rest of the countries (Finland and Great Britain) the collected views have been extremely different.

Answering the question posed in the part of the article including its aim which concerned the degree of similarity of cultural traits among the researched persons it should be unambiguously stated that this degree is high. Young Europeans, irrespective of which country and culture they come from, are characterized by similar traits. At this point it is also advisable to demonstrate the results of the research conducted among the people aged 19-29 in Lithuania and Latvia, in which the Hofstede's indexes were used. It is worth noting that as far as each dimension is concerned these results are analogous to the results obtained in the discussed research [Huettinger M., 2008, pp. 370-372]. What is more, while referring to the results of other researchers presented in the theoretical part of this article they are extremely analogous to the results of the studies concerning generation $\mathrm{Y}$ in general [Solnet D., Hood A., 2008; Chi Ch.G. et al. 2013; Broadbridge A.M. et al. 2007; Kwok H., 2012; Altimier L., 2006].

In the next part of the analysis a question should be asked whether in a few years the same respondents, as managers in enterprises, will present the same views, traits and values. The answer to this question is not unambiguous and it is an interesting point for further research and studies. It may turn out that the similarity in views is influenced by age and little work experience, and consequently after a few years the same respondents will show different attitudes. On the other hand, it may turn out that convergent processes and globalization will influence the increase in the similarity of traits of people representing other cultures. 


\section{Bibliography}

Altimier, L. (2006) 'Leading a New Generation', Newborn and Infant Nursing Reviews, vol. 6, no. 1 (March), pp. 7-9.

Bartosik-Purgat, M. (2011) Kulturowe uwarunkowania zachowan konsumentów na przyktadzie młodych Europejczyków, Poznań: Wyd. UEP.

Broadbridge, A. M., Maxwell, G. A. and Ogden, S. M. (2007) 'Students' view of retail employment: Key findings from generation Y's", International Journal of Retail and Distribution Management, no. 35, pp. 982-992.

Chi, Ch.G., Maier, T.A. and Gursoy, D. (2013) 'Employees' perceptions of younger and older managers by generation and job category', International Journal of Hospitality Management, no. 34, pp. $42-50$.

Choi, M. and Ferle C.L. (2004) 'Convergence across American and Korean young adults: socialisation variables indicate the verdict is still out', International Journal of Advertising, no. 23, pp. 479-506.

Clausen, L. (2010) 'Moving beyond stereotypes in managing cultural difference: Communication in Danish - Japanese corporate relationships', Scandinavian Journal of Management, vol. 26, pp. 57-66.

Dong, K. and Liu Y. (2010) 'Cross-cultural management in China', Cross Cultural Management: An International Journal, vol. 17 no. 3, pp. 223-243.

Gesteland, R.R. (2001) Cross-Cultural Business Behavior. Marketing Negotiating and Managing Across Cultures, Copenhagen: Copenhagen Business School Press.

Gupta V. and Wang J. (2004), 'The Transvergence Proposition Under Globalization: Looking Beyond Convergence, Divergence and Crossvergence', Multinational Business Review, vol. 12 no. 2 , pp. $37-58$.

Gursoy, D., Chi, C. and Karadag, E. (2013) 'Generational differences in work values and attitudes among frontline and service contact employees', International Journal of Hospitality Management, vol. 32 no. 1, pp. 40-48.

Hofstede, G. (1997) Cultures and Organizations. Software of the Mind, New York: McGRAWHill.

Hoque, F., Walsh, L.M., Mirakaj, D.L. and Bruckner, J. (2011) The Power of Convergence : Linking Business Strategies and Technology Decisions to Create Sustainable Success, New York: American Management Association.

House, R., Javidan, M., Hanges, P. and Dorfman, P. (2002) 'Understanding cultures and implicit leadership theories across the globe: an introduction to project GLOBE', Journal of World Business, no. 37, pp. 3-10.

Huettinger, M. (2008) 'Cultural dimensions in business life: Hofstede's indices for Latvia and Lithuania, Baltic Journal of Management, vol. 3 no. 3, pp. 359-376.

Jacob, N. (2005) 'Cross-cultural investigations: emerging concepts', Journal of Organizational Change Management, vol. 18 no. 5, pp. 514-528. 
Kanungo, R.P. (2006) 'Cross culture and business practice: are they coterminous or crossverging?’, Cross Cultural Management: An International Journal, vol. 13 no. 1, pp. 23-31.

Kirsch, Ch., Chelliah, J. and Parry W. (2012) 'The impact of cross-cultural dynamics on change management, Cross Cultural Management, vol. 19 no. 2, pp. 166-195.

Klein, N. (2004) No logo, Izabelin: Wyd. Świat literacki.

Kwok, H. (2012) 'The Generation Y’s Working Encounter: A Comparative Study of Hong Kong and other Chinese Cities', Journal of Family and Economic Issues, no. 33, pp. 231-249

Lee, S.M. and Peterson, S.J. (2000) 'Culture, Entrepreneurial Orientation, and Global Competitiveness', Journal of World Business, vol. 35 no. 4, pp. 401-416.

Minkov, M. and Hofstede, G. (2001) 'The evolution of Hofstede's doctrine', Cross Cultural Management: An International Journal, vol. 18 no. 1, pp. 10-20.

Ogbor, J.O. (2000) 'Organizational leadership and authority relations across cultures: beyond divergence and convergence`, International Journal of Commerce and Management, vol. 10, no. 1 , pp. $48-73$

Ogbor, J.O. and Williams, J. (2003) 'The cross-cultural transfer of management practices: the case for creative synthesis, Cross Cultural Management, vol. 10 no. 2, pp. 3-23.

Pamar, A. (2002) 'Global youth united: homogeneous group prime target for U.S. marketers', Marketing News, 28 October, pp. 1 -49.

Schroeder, J., Bartosik-Purgat, M. and Mruk, H. (2013) Mięzynarodowe badania marketingowe, Poznań: Wyd. UEP.

Solnet, D. and Hood, A. (2008), 'Generation Y as hospitality employees: framing a research agenda', Journal of Hospitality and Tourism Management, vol. 15, pp. 59-68.

Trompenaars, F. and Hampden-Turner, Ch. (1997), Riding the Waves of Culture. Understanding Diversity in Global Business, New York: McGraw-Hill Publ..

Wendover, R.W. (2007) 'Getting Millennials to engage', Personality and Social Psychology, vol. 73 no. 1, pp. 73-90.

Yeganeh, H. (2013) 'A compound index of cultural dimensions: implications and applications', International Journal of Organizational Analysis, vol. 21 no. 1, pp. 53-65.

Yeganeh, H. (2011) 'A generic conceptualization of the cultural distance index. Application to Schwartz's and Hofstede's frameworks', Journal of Strategy and Management, vol. 4 no. 4, pp. 325-346.

Živko, T. (2006) 'The economic-cultural context of the EU economies', Kybernetes, vol. 35 No. 7/8, pp. 1024-1036. 